\title{
RANCANG BANGUN APLIKASI E-PORTOFOLIO HASIL KARYA MAHASISWA UNSERA MENGGUNAKAN METODE SCRUM
}

\author{
Donny Fernando ${ }^{1}$, Anharudin ${ }^{2}$, Fadli $^{3}$ \\ ${ }^{\text {I} P r o g r a m ~ S t u d i ~ T e k n i k ~ I n f o r m a t i k a ~ F a k u l t a s ~ T e k n o l o g i ~ I n f o r m a s i ~ U n i v e r s i t a s ~ S e r a n g ~ R a y a ~}$ \\ ${ }^{2}$ Program Studi Sistem Komputer Fakultas Teknologi Informasi Universitas Serang Raya \\ ${ }^{3}$ Program Studi Sistem Informasi Fakultas Teknologi Informasi Universitas Serang Raya \\ Jalan Raya Serang-Cilegon KM. 5 Taman Drangong Serang, Banten \\ mr.donny2008@gmail.com \\ anhar.dean@gmail.com \\ kimtaro06@gmail.com
}

\begin{abstract}
Abstrak - Zaman digital yang semakin berkembang di era globalisasi seperti sekarang ini menuntut sebuah institusi, lembaga maupun organisasi untuk memanfaatkan sebuah sistem yang baik didalam pengelolaan data, hal ini sangat diperlukan agar kumpulan data atau dokumen yang sangat banyak jumlahnya dapat terorganisir dengan baik dan rapih. institusi seperti kampus yang besar, sangat memerlukan diterapkannya sistem e-filing agar dokumen penting, terutama hasil karya mahasiswa dapat di kelola dengan baik, oleh karenanya dibutuhkan sebuah Sistem aplikasi E-portofolio hasil karya mahasiswa yang memanfaatkan kemajuan Teknologi Informasi dan Komunikasi (TIK) dibidang komputer. Tujuannya agar hasil karya mahasiwa yang pernah dibuat dapat ditampung kedalam sebuah aplikasi kemudian dapat dipublikasikan. sehingga dapat diketahui oleh beberapa pihak baik pihak Unsera, Mahasiswa dan masyarakat umum. Penelitian ini menggunakan metode Scrum. Dengan aplikasi E-portofolio hasil karya mahasiswa diharapkan dapat membantu beberapa pihak karena dapat dijadikan sebagai bahan acuan untuk menghasilkan sebuah referensi atau karya baru. Hasil yang diperoleh dari penelitian ini adalah Rancang bangun aplikasi Eportofolio hasil karya mahasiswa Unsera.yang selanjutnya akan diterapkan di kampus Universitas Serang Raya.
\end{abstract}

Kata kunci : Rancang Bangun Aplikasi, E-Portofolio, Scrum

\section{PENDAHULUAN}

Universitas Serang Raya (UNSERA) adalah kampus terpadu swasta yang ada di Kota Serang-Banten, tujuan berdirinya kampus ini adalah untuk menyediakan pendidikan tingkat Universitas. UNSERA kampus pada umumya untuk dapat lulus perkuliahan harus melewati ujian yang sering disebut dengan Skripsi, Skripsi adalah laporan akhir mahasiswa sebagai syarat untuk dapat lulus kuliah dan dibuat dengan tahap beberapa penelitian yang sudah dibukukan, Selain hasil karya ilmiah dibidang penelitian ada juga hasil karya mahasiswa berupa produk jadi seperti pembuatan Robotik, Aplikasi (Software) dan hasil rancangan lainnya.

Hasil karya dan produk mahasiswa terdapat suatu permasalahan yang perlu diperhatikan, yaitu hasil karya mahasiswa belum tentu diketahui oleh banyak pihak antara lain dosen dan mahasiswa lainya. Karena sampai saat ini hasil karya mahasiswa Unsera sebagian hanya ditampung sebatas lewat perpustakaan kampus dalam bentuk buku (Skripsi) sehingga kurang dipublikasikan, hasil karya dan produk mahasiswa ini harus diketahui oleh beberapa pihak karena dapat dijadikan sebagai bahan acuan untuk menghasilkan karya lain atau referensi yang bermanfaat bagi mahasiswa atau masyarakat umum.

Oleh karena itu pada penelitian ini peneliti membahas tentang pembuatan E-Portofolio hasil karya mahasiswa UNSERA, adalah aplikasi khusus untuk penampungan informasi hasil karya mahasiswa UNSERA yang berbasis web, yang bertujuan untuk mengumpulkan informasi produk atau hasil karya mahasiswa UNSERA baik itu kategori mahasiswa aktif, alumni, Unit Kegiatan Mahasiswa (UKM) dan Himpunan Mahasiswa Jurusan 
(HMJ). dan diharapkan dengan adanya aplikasi E-portofolio hasil karya mahasiswa Unsera dapat bermanfaat bagi beberapa pihak baik pihak kampus, mahasiswa dan masarakat umum. sehingga penelitian ini diberi judul: "RANCANG BANGUN APLIKASI E-PORTOFOLIO HASIL KARYA MAHASISWA UNSERA MENGGUNAKAN METODE SCRUM $"$.

\section{METODOLOGI PENELITIAN}

Metode pengembangan sistem yang digunakan adalah Metode Scrum Pada bagian ini penulis akan mengimplementasikan metodologi scrum pada pengembangan Aplikasi E-Portofolio Hasil Karya Mahasiswa dengan scrum team yang telah ditentukan sebelumnya. Tahapan-tahapan yang digunakan yaitu seperti gambar berikut:

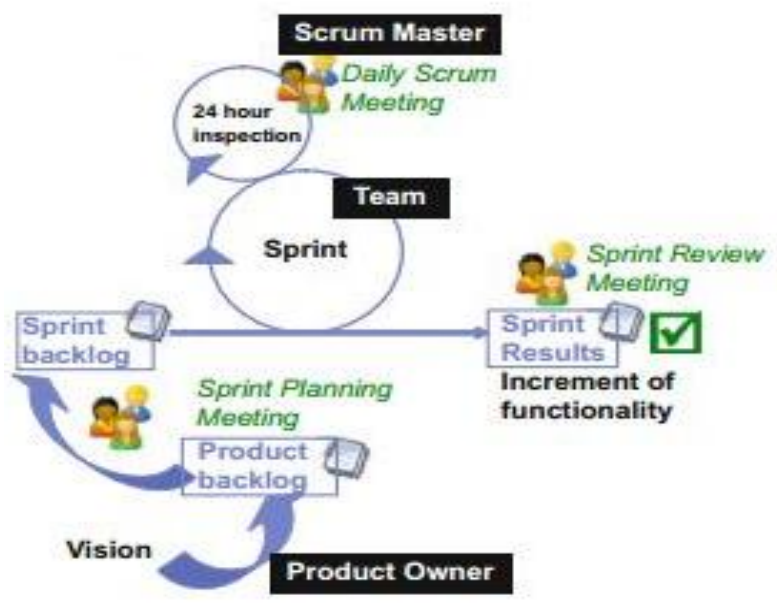

Gambar 1. Alur Metode Scrum

Scrum dikembangkan oleh Jeff Sutherland pada tahun 1993 dan yang Tujuannya adalah untuk menjadi pengembangan dan manajemen metodologi yang mengikuti prinsip-prinsip metodologi Agile. Scrum adalah sebuah kerangka kerja responsif tambahan perangkat lunak pengembangan untuk proyek-proyek perangkat lunak dan mengelola produk atau pengembangan aplikasi. Fokusnya adalah pada "strategi, fleksibel pengembangan produk holistik di mana tim pengembangan bekerja sebagai unit untuk mencapai tujuan bersama" sebagai lawan" Pendekatan tradisional, urutan". Scrum memiliki kompleks proses di mana banyak faktor yang mempengaruhi hasil akhir. Aktivitas-aktivitas meeting yang dilakukan pada Scrum setidaknya ada 5 jenis, yaitu Backlog Grooming, Sprint Planning, Daily Scrum, Sprint Review dan Sprint Retrospective. Masing-masing aktivitas memiliki definisi dan tujuan masing-masing.

\section{HASIL DAN PEMBAHASAN}

\subsection{Aplikasi E-Portofolio Hasil Karya Mahasiswa}

Aplikasi E-Portofolio adalah suatu sistem yang dirancang untuk keperluan pengelolaan data-data hasil karya mahasiswa dengan penerapan teknologi komputer baik hardware maupun software, sehingga seluruh proses kegiatan dapat terkelola menjadi informasi yang bermanfaat dalam pengelolaan E-Portofolio hasil karya mahasiswa. terdapat beberapa

pengguna yang memiliki tugas dan akses berbeda pada perangkat lunak yang akan dibangun. Peran tersebut dibagi menjadi beberapa, yaitu:

a. Administrator : bertugas untuk mengelola system secara keseluruhan.

b. Dosen : bertugas untuk mengelola data hasil karya mahasiswa (E- Portofolio)

c. Mahasiswa : Melihat hasil karya dan upload hasil karyanya ke website.

d. Guest User : Melihat hasil karya mahasiswa.

3.2 Pengembangan Aplikasi E-Portofolio Hasil Karya Mahasiswa Unsera Menggunakan Metode Scrum

1. Menentukan Product Backlog

Langkah pertama dari Scrum adalah penentuan dari fitur berdasarkan priotitasnya oleh manajer proyek. Berikut adalah daftar dari fitur-fitur yang akan dibangun sesuai prioritasnya

Tabel 1. Tabel Product Backlog

\begin{tabular}{|c|l|}
\hline No & \multicolumn{1}{|c|}{ Analisis kebutuhan } \\
\hline $\mathbf{1}$ & Analisis kebutuhan sistem \\
\hline $\mathbf{2}$ & Analisis kebutuhan hardware dan software \\
$\mathbf{3}$ & Analisis sistem yang akan berialan \\
\hline $\mathbf{4}$ & Rancangan antarmuka sistem \\
$\mathbf{5}$ & Coding program aplikasi \\
\hline $\mathbf{6}$ & Testing \\
\hline
\end{tabular}

\section{2. $\quad$ Sprint Planning Meeting}

Setelah mementukan Product Backlog diadakan briefing/rapat oleh scrum team di setiap awal Sprint untuk mengevaluasi Product Backlog, mendiskusikan tujuan dan misi dari tiap fitur sesuai dengan keinginan Product Owner. Pada bagian ini, setiap anggota Scrum Team menentukan berapa jam yang dibutuhkan tiap anggota untuk melaksanakan pekerjaan pada tiap fiturnya. Berikut adalah contoh dari penerapan Sprint Planning Meeting. 
Tabel 2. Tabel Sprint Planning Meeting

\begin{tabular}{|c|l|}
\hline \multicolumn{1}{|c|}{ No } & Deskripsi Fitur \\
\hline $\mathbf{1}$ & Upload pengajuan HKM \\
\hline $\mathbf{2}$ & Validasi HKM \\
\hline $\mathbf{3}$ & View HKM \\
\hline $\mathbf{4}$ & laporan HKM \\
\hline $\mathbf{5}$ & Data mahasiswa \\
\hline $\mathbf{6}$ & Data dosen pembimbing \\
\hline 7 & Login \\
\hline
\end{tabular}

\section{Sprint Backlog}

Waktu kerja tim yang sudah ditentukan dibagi lagi menjadi beberapa tugas bagi setiap anggota tim, dan disebut dengan Sprint Backlog. Pada bagian ini, setiap anggota tim mendapatkan pembagian waktu untuk menyelesaikan fitur yang sudah didefiniskan di Product Backlog. Detailnya dapat dilihat pada tabel dibawah ini.

Tabel 3. Tabel Sprint Backlog

\begin{tabular}{|c|c|c|}
\hline Analisis sistem dan designer & Programer & Manager provek \\
\hline Analisis kebutuhan sistem & Coding program aplikasi & Testing \\
\hline $\begin{array}{l}\text { Analisis kebutuhan hardware } \\
\text { dan software }\end{array}$ & & \\
\hline Analisis sistem yang berjalan & & \\
\hline Rancangan antarmuka sistem & & \\
\hline
\end{tabular}

\section{Daily Scrum}

Sebagai praktik untuk memantau kinerja, setiap hari perlu diadakan meeting untuk pelaporan apa saja yang sudah tiap anggota tim kerjakan. Pada tahap ini tidak semua anggota tim harus hadir, namun lebih kepada anggota yang terlibat khusus pada fitur yang sedang dikembangkan. Pada setiap akhir meeting, waktu penyelesaian diperbaharui untuk mengetahui sisa pengerjaan yang harus dikejar selama Sprint berjalan.

\section{Sprint Result}

Sprint Result adalah hasil yang diperoleh dari kegiatan Sprint yang telah berjalan.

\section{Sprint Review Meeting}

Sprint Review Meeting yaitu mengulas kembali hasil dari Sprin Result apakah produk sudah

\subsection{Analisis Sistem Yang Dibangun}

Analisis Sistem yang akan dibangun pada Universitas Serang Raya yaitu mengintegrasikan semua data mengenai Mahasiswa dan Hasil Karya Mahasiswa ke dalam suatu database terpusat. Yang akan lebih memudahkan Dosen untuk menampung mengenai Data Hasil Karya Mahasiswa. berikut gambaran pengembangan sistem dalam bentuk UML (unified modeling Language).

a. Use Case Diagram

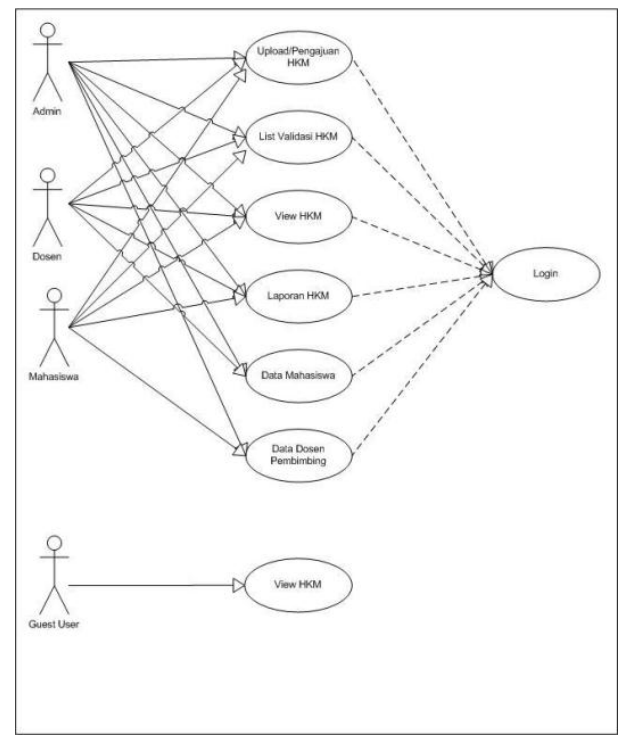

Gambar 2. Use Case Diagram

b. Class Diagram

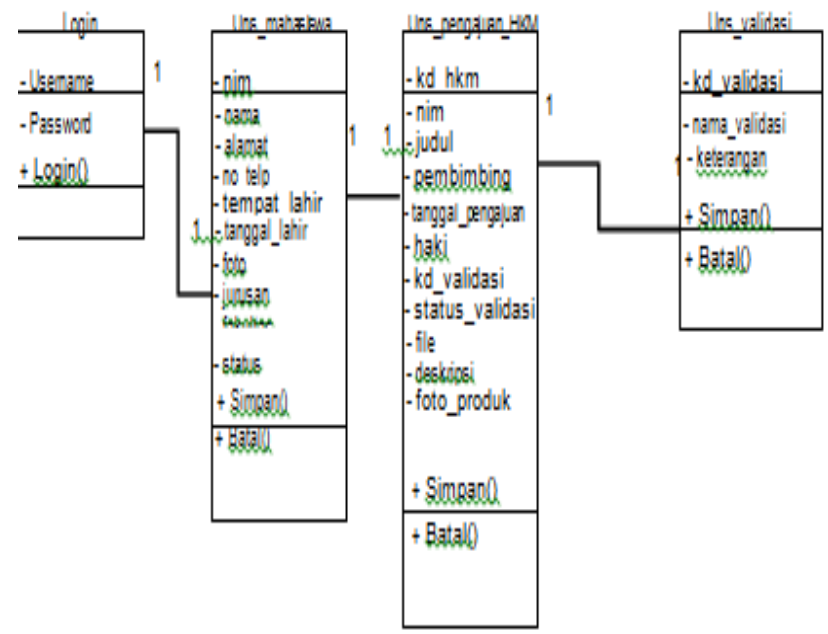

Gambar 3. Class Diagram

a. Halaman Utama

Halaman utama adalah halaman proses awal yang di tampilkan saat pembuatan aplikasi E- 
Portofolio hasil karya mahasiswa Unsera mulai dijalankan. Masing-masing user dapat menggunakan menu pada panel tersebut dengan melakukan login terlebih dahulu.

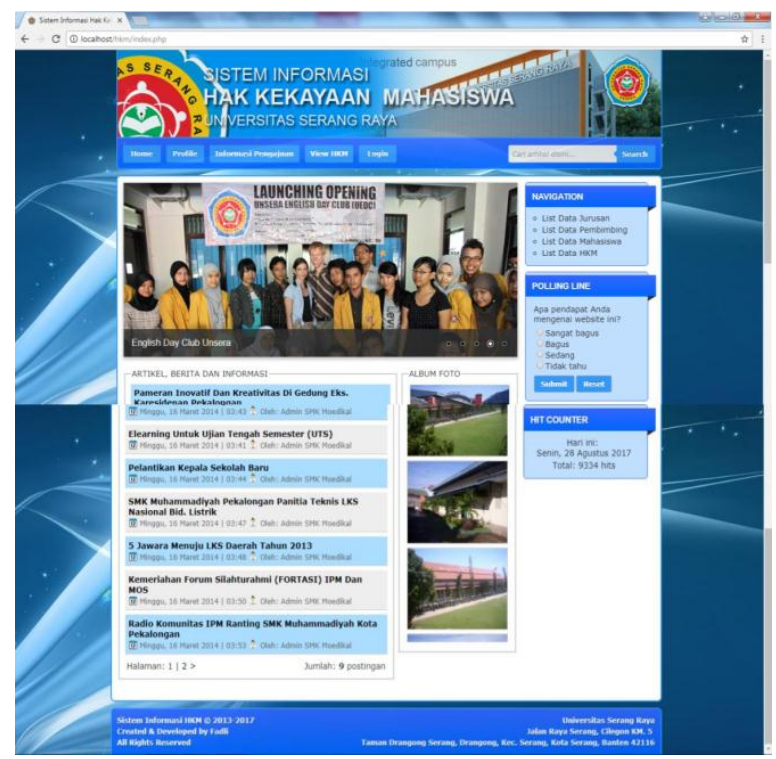

Gambar 4. Halaman Utama

b. Halaman Login

Halaman Login menggambarkan bagaimana melakukan registrasi, user dapat memilih jenis hak diantaranya Administrator, Dosen atau Mahasiswa

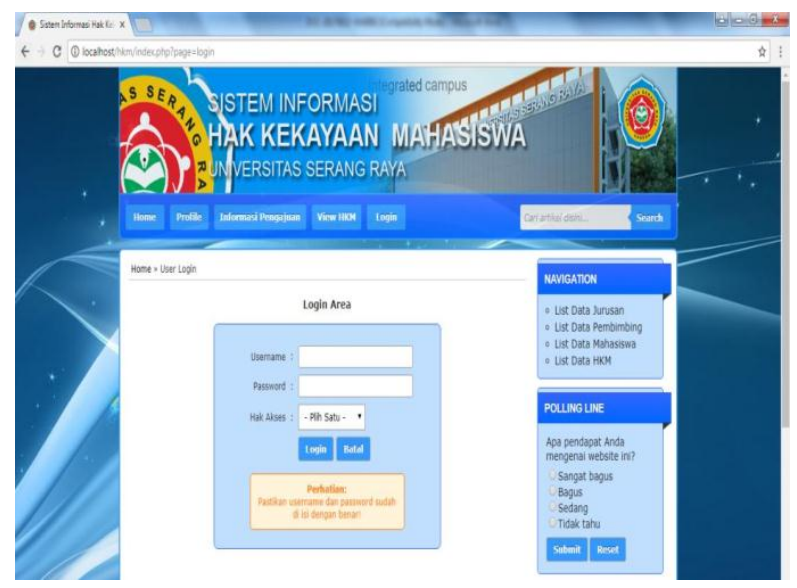

Gambar 5. Halaman Log In

c. Halaman Panel mahasiswa

Halaman panel mahasiswa menggambarkan menu-menu yang ada pada panel mahasiswa.

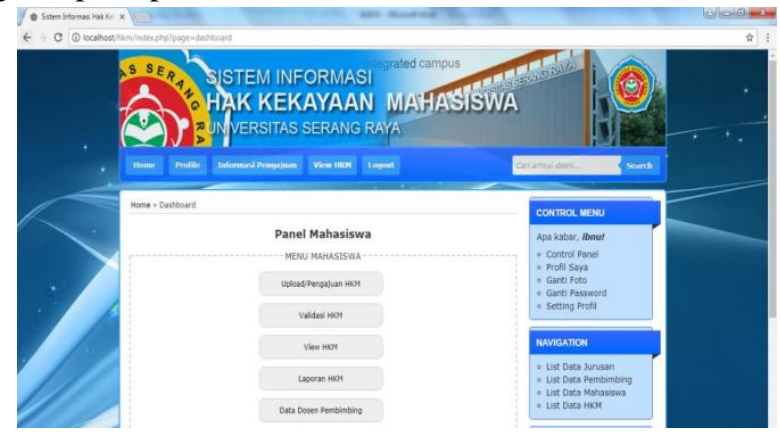

Gambar 6. Halaman Panel Mahasiswa

d. Halaman panel dosen

Halaman panel dosen menggambarkan menu-menu yang ada pada panel dosen

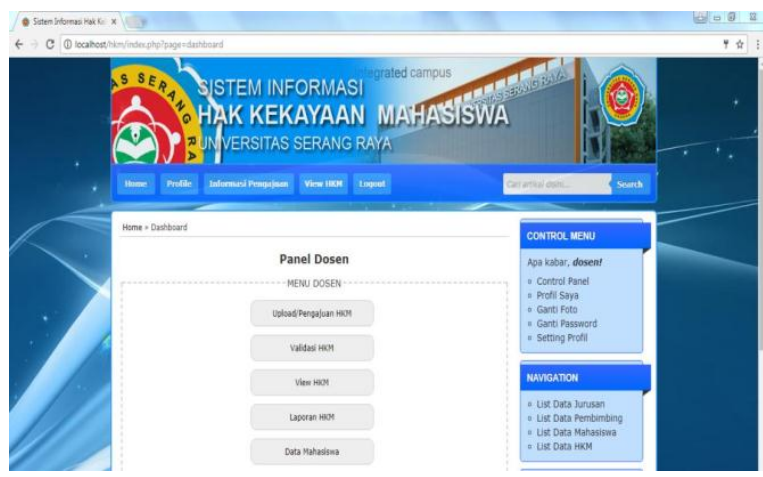

Gambar 7. Halaman Panel Dosen

e. Halaman panel Admin

Halaman panel Admin menggambarkan menu-menu yang ada pada panel Admin

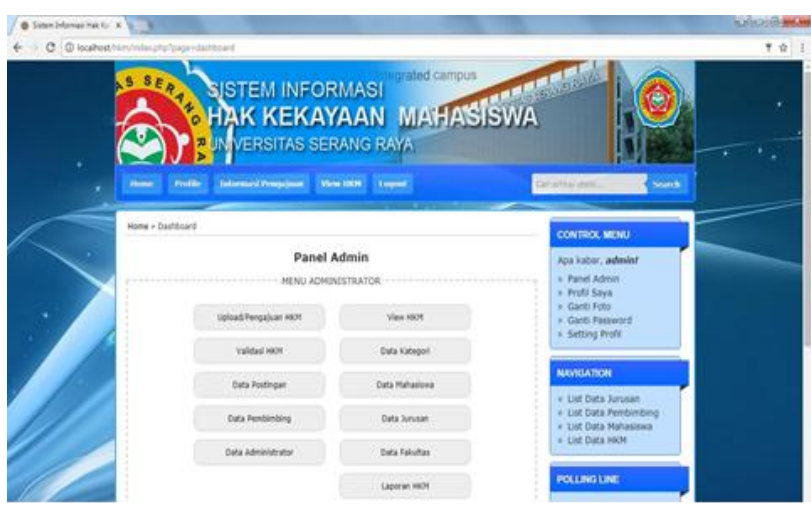

Gambar 8. Halaman Panel Admin

f. Halaman Upload/Pengajuan HKM

Halaman upload/pengajuan HKM menggambakan bagaimana Mahasiswa dapat melakukan tambah data

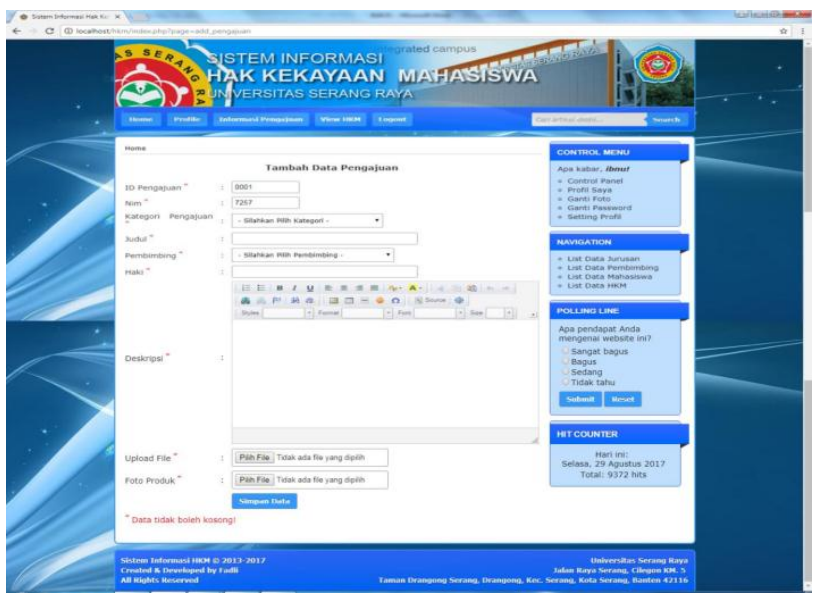

Gambar 9. Halaman Upload HKM 
g. Halaman Validasi HKM

Halaman Validasi HKM Menggambarkan bagaimana mahasiswa melakukan validasi terhadap HKM nya.

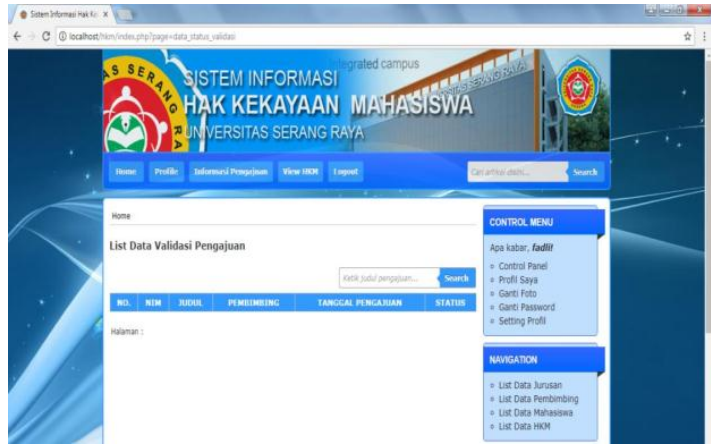

Gambar 10. Halaman Validasi HKM

h. Halaman View HKM

Halaman view HKM menggambarkan bagaimana Mahasiswa mampu melihat daftar HKM yang telah tervalidasi yang sebelumnya telah diajukan

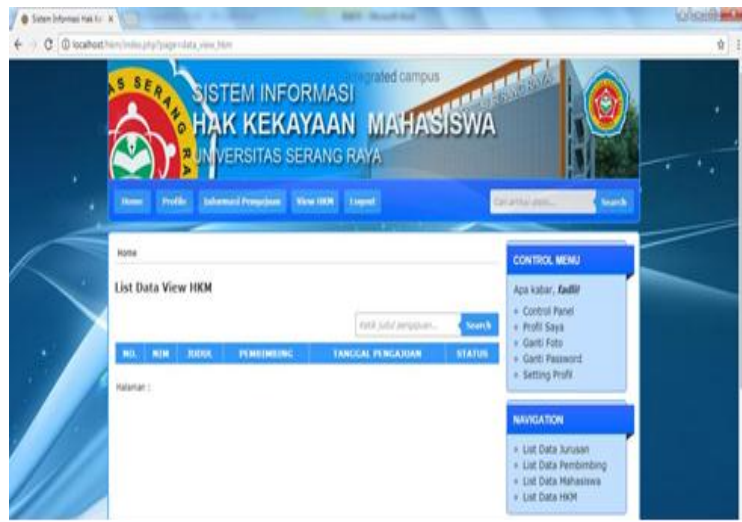

Gambar 11. View HKM

i. Laporan HKM

Halaman Laporan HKM Mampu menampilkan kategori pencarian data HKM yang telah tersimpan di dalam database yang sebelumnya telah diajukan

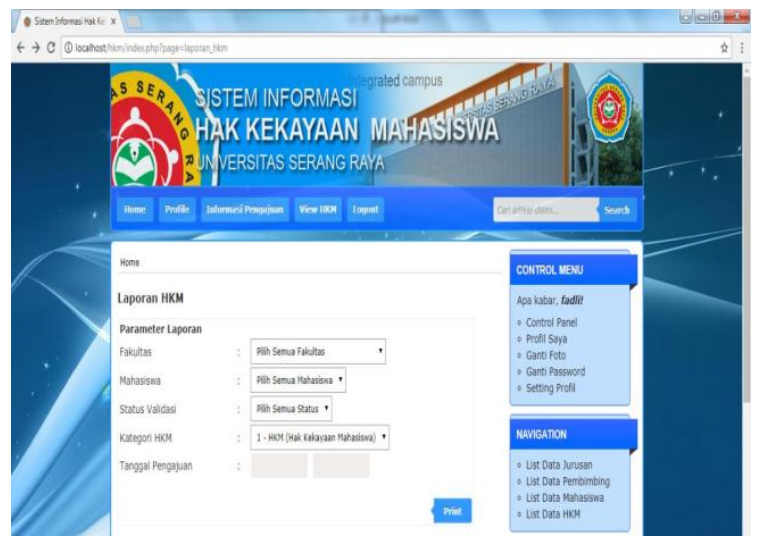

j. Data Mahasiswa

Gambar 12. Laporan HKM

Halaman data mahasiswa menampilkan seluruh data mahasiswa yang telah terdaftar di dalam database

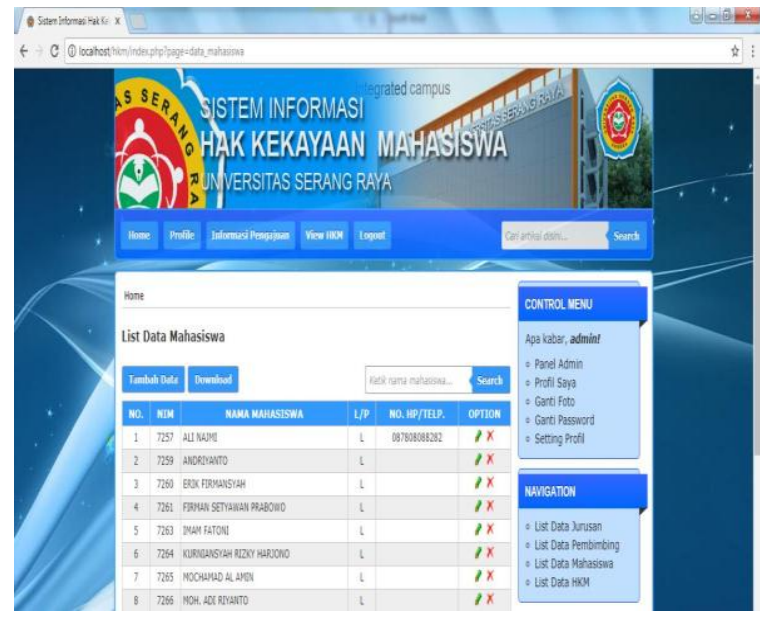

Gambar 13. Data Mahasiswa

k. Data Dosen Pembimbing

Halaman Data Dosen Pembimbing menampilkan seluruh data Dosen pembimbing yang telah terdaftar di dalam database

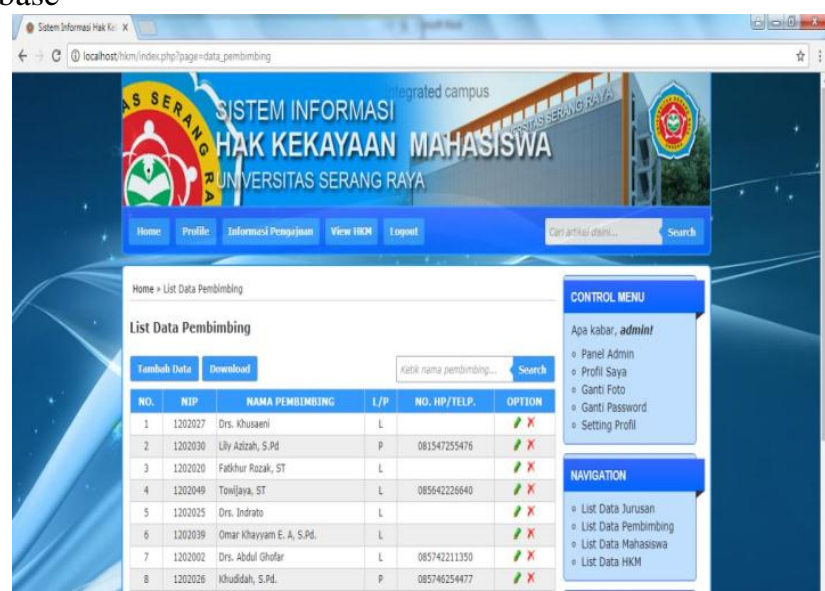

Gambar 14. Data Dosen Pembimbing

\section{KESIMPULAN}

a. Kesimpulan

Berdasarkan uraian dan pembahasan dari bab-bab sebelumnya, maka diambil kesimpulan bahwa merancang dan membangun aplikasi E-Portofolio hasil karya mahasiswa pada Universitas Serang Raya dapat ditempuh dengan menggunakan metode Scrum dan dibutuhkan bahasa pemrograman $W e b$ yaitu $P H P+M y S Q L$ dan perancanganya menggunakan $U M L$. Dan diperlukan koneksi internet beserta template website HTML5 boostrap responsive sehingga aplikasi E-portofolio dapat diakses dimana saja dan kapan saja, untuk View hasil karya mahasiswa berbentuk jurnal menggunakan format PDF sehingga aman dari orang yang tidak bertanggung jawab. 
b. Saran

Untuk pengembangan aplikasi ini kedepanya, berikut beberapa saran yang dianjurkan :

1. Untuk kedepanya Pihak Universitas dapat mengwajibkan mahasiswanya untuk meng upload hasil karyanya pada aplikasi tersebut.

2. Aplikasi ini bisa ditambahkan fitur donasi mahasiswa pada guest user dengan sistem pembayaran Paypal.

3. Sistem pada aplikasi ini bisa dikembangkan dengan versi android

\section{REFERENSI}

[1] Andi. (2003). WEB HACKING serangan dan pertahananya. Yogyakarta: Perpustakaan Nasional.

[2] Dennis, Alan, Wixom dan Roth. (2012). "Systems Analysis and Design with UML -5th Edition".

[3] Fahmi, I. (2015). Pengantar Teori Portofolio dan Analisis Investasi. Bandung: ALFABETA.

[4] Krisnanda, M. (2014). Implementasi Metodologi SCRUM dalam Pembangunan . Jurnal Sistem Informasi, Vol. 9 No. 2, 149.

[5] Nurdin Ibrahim, H. W. (2016). Pemetaan Fungsi Platforn E-Portofolio Untuk Perkuliahan Di jurusan Kurikulum dan Teknologi Pendidikan Fakultas Ilmu Pendidikan Universitas Negri Jakarta. Jurnal Teknologi Pendidikan Vol. 18, No. , 202.

[6] Nurhayati, F. R. (2014). Pengembangan E-Portofolio Sebagai Instrumen Penelitian Siswa. Jurnal Pendidikan Teknik Elektro, 253.

[7] Partogi, J. (2015). Managemen Modern Dengan SCRUM. Yogyakarta: Andi.

[8] Permana, P. A. (2015). Scrum Method Implementation in a Software Development Project Management. (IJACSA) International Journal of Advanced Computer Science and Applications, 198.

[9] Ramlawati, D. (2012). Pengembangan Model Assesmen Portofolio Elektronik (APE) untuk Meningkatkan. Jurnal Chemica Vol.13 nomor 1, 31 .

[10] Soetam Rizky, 2011, Konsep dasar Rekayasa Perangkat Lunak (software engineering) Jakarta

[11]Thomas Stober, U. H. (2010). Agile Software Development. Berlin: Springer.

[12] Unsera. (2017, September, Rabu). profil unsera. Dipetik September 13, 2017, dari www.unsera.ac.id: www.kampus-info.com/2012/02/profil-universitasserang-raya.html?m=1 22 juni 2017 